\section{Fruition of flowering plants}

\author{
Sorry, for copyright \\ reasons some images \\ on this page may not \\ be available online
}

The Morphology of Angiosperms : The Structure and Evolution of Flowering Plants. By K. R. Sporne. Pp. 207. (Hutchinson: London, February 1975.) $£ 3.50$ cased; $£ 2.00$ paper.

THE study and interpretation of plant morphology is a subject which captured the imagination, and occupied much of the research effort, of botanists of the nineteenth century. Yet within the last few generations the emphasis of teaching and research has swung away from the structural and toward the physiological, biochemical and ecological aspects of the subject. Although such emphases are bound to change as new techniques and ideas come to prominence, it is sad that so many of those who teach in our schools and universities have come to regard all matters structural as the descriptive studies of a former era and therefore irrelevant to their needs. Even the word 'descriptive' is held in disrepute in some quarters. Undoubtedly the lack of a good modern synthesis of morphological concepts has contributed to this situation and for this reason Sporne's trilogy of morphological texts is especially to be welcomed.

This final book, dealing with the angiosperms (previous ones have covered pteidophytes and gymnosperms), couples a careful selection of information with a lively and readable style- both nccessary attributes of a book which seeks both to enlighten and to interest the student. The arrangement of its contents is traditional, dealing with embryology, then the major structural features of the angiosperms, meristems, root, shoot, pollen, ovules, seeds, and so on. Yet the material of this book is conveyed in a far from traditional manner. There is a strong underlying theme of evolutionary trends, which both provides a unity to the examples quoted and also serves to raise those basic questions of origins which should be central in the minds of all biologists. Sporne's book excells in that he is prepared to raise these questions and attempts to answer them cven at the risk of overgeneralisation.

The paucity of fossil records relevant to angiosperm phylogeny means that comparative morphology is still the most useful approach to the questions of evolution within the group. Sporne describes the modern numerical work in this field and, although he recognises its weaknesses, can unashamedly state that "a policy of caution would take half of the fun out of research". Perhaps it is the overcautious approach of his predecessors which has taken much of the fun out of plant morphology, but this lively, informative and entertaining book should succeed in injecting some renewed vigour into this neglected subject. It will be weclomed, and should be read by all students and teachers in the field of plant biology.

P. D. Moore

\section{Science as an obstacle course}

Problems of Scientific Revolution: Progress and Obstacles to Progress in the Sciences. (The Herbert Spencer Lectures 1973.) Edited by Rom Harré. Pp. vit 104. (Clarendon: Oxford; Oxford University: London, July 1975.) Paper $£ 1.75$ net; Boards $£ 4.00$ net.

I Must be honest. I have never actually managed to get around to reading much philosophy of science, except for Medawar in passing. My reactions to this book are therefore probably akin to those students who listened to the 1973 Herbert Spencer lectures recorded therein. I hcpe it is not through naivety that I found most of the lectures coherent and stimulating.

The book has six contributors ranging from practising scientists to professional philosophers. The mixture works well, allowing a wide-angle approach to the subject. As I cannot believe that it is a sine qua non of thinking scientists that they subscribe to the views of Sir Karl Popper, however, it is perhaps surprising that four of the six writers are self-confessed Popperians, another one is guru Popper himself, and only B. F. Skinner does not pay explicit homage.

The progress of science is viewed at its most practical level by W. F. Bodmer. He exemplifies the external factors, especially ethical and eugenic, that modulate the progress of genetics and concludes with rather hackneyed advice to scientists on how to assume a socially responsible position. Sir $\mathrm{Her}$ mann Bondi is more concerned with the internal forces that operate. He reveals, again by example, the kind of fits and starts involved in any scientific advance and correctly emphasises the reliance of progress on new technology.

The development of evolutionary theory is Jacques Monod's theme. He shows how the coming of molecular biology has not only added unpredictable layers of flesh to the bones of Huxley's synthetic theory but has at the same time converted it into a theory fully liable to Popperian falsification. He also attacks his critics who cannot come to terms with the advent of man by chance, and not by necessity. B. F. Skinner is even more critical of those who cannot overcome the obstacles he sees to the progress of behavioural science. Their fault, he argues with clarity, is in being trapped by an introspective, reductionist approach. Unfortunately he fails to develop his own alternative approach and its controversial application to, for example, behavioural modification.

The least tangible of the contributions is that in which J. R. Ravetz suggests that the way to salvation for the present condition of science lies in the spirit of Francis Bacon. The longest essay, replete with footnotes, is Popper's. It is divided into two parts. The first is concerned with his fallibilist theory but with several unexpected diversions. The second part deals with hindrances to scientific progresseconomic factors ("big science may destroy great science"), intolerance plus dogmatism and, most pernicious, the danger of allowing scientific revolutions to become blurred by ideological entrenchment or the fashionmongering of intellectuals.

This book is ideal for undergraduates or postgraduates. By and large it avoids being doctrinaire and is sufficiently down to earth to have a lasting and beneficial influence on its readers.

Peter Newmark

Science Between Culture and CounterCulture. By C. I. Dessaur, Aren Naess, Everett Reimer, Hans J. Eysenck and A. G. M. van Melsen. Pp. 108. (Dekker and van de Vegt: Nijmegen, 1975.) Dit. 19.50 .

THE debate that has developed in 